\title{
Impact of tumour histology on survival in advanced cervical carcinoma: an NRG Oncology/Gynaecologic Oncology Group Study
}

Leigh G Seamon ${ }^{\star}, 1$, James J Java ${ }^{2}$, Bradley J Monk ${ }^{3}$, Richard T Penson ${ }^{4}$, Jubilee Brown ${ }^{5}$, Robert S Mannel ${ }^{6}$, Anna Oaknin ${ }^{7}$, Mario M Leitao ${ }^{8}$, Eric L Eisenhauer ${ }^{9}$, Harry J Long ${ }^{10,4}$, Shu Y Liao ${ }^{11}$ and Krishnansu S Tewari ${ }^{11}$ ${ }^{1}$ Divisions of Gynecologic Oncology, Spectrum-Health Hospital Group and Michigan State University College of Human Medicine, Lemmen Holton Cancer Pavilion, 145 Michigan Street, NE; Suite 6300, Grand Rapids, MI 49503, USA; ${ }^{2}$ NRG Oncology/ Gynecologic Oncology Group Statistics and Data Center, Buffalo, NY 14263, USA; ${ }^{3}$ University of Arizona Cancer Center, Phoenix Creighton University School of Medicine, Phoenix, AZ 85013, USA; ${ }^{4}$ Massachusetts General Hospital, Boston, MA 02114, USA; ${ }^{5}$ MD Anderson Cancer Center, Houston, TX 77030, USA; ${ }^{6}$ The University of Oklahoma Health Sciences Center, Oklahoma City, OK 73117, USA; ${ }^{7}$ Vall d'Hebron University Hospital, Vall d'Hebron Institute of Oncology (VHIO), Barcelona 080350, Spain; ${ }^{8}$ Memorial Sloan-Kettering Cancer Center, New York, NY 10065, USA; ${ }^{9}$ University of Cincinnati, Cincinnati, OH 45220, USA; ${ }^{10}$ Mayo Clinic, Rochester, MN 55902, USA and ${ }^{11}$ Department of Pathology (SL) and Department of Gynecologic Oncology (KT), Irvine Medical Center, University of California, Orange, CA 92868, USA

Background: Based primarily on studies concerning early-stage tumours (treated surgically), and locally advanced disease (treated with chemoradiation), the prognosis for women with adenocarcinoma (AC) or adenosquamous (AS) carcinoma has been reported to be poorer than those with squamous cell carcinoma (SCCA) of the cervix. It is unclear whether differences in prognosis also persist in the setting of recurrent or metastatic disease treated using chemotherapy doublets with or without bevacizumab.

Methods: Cases were pooled from three Gynaecologic Oncology Group randomised phase III trials of chemotherapy doublets. Pearson's test was used to evaluate response rate (RR) of AC/AS vs SCCA, Kaplan-Meier method to estimate progression-free survival (PFS) and overall survival (OS), and Cox proportional hazards model to estimate the impact of histology on PFS and OS.

Results: Of 781 evaluable patients, 77\% ( $N=599)$ had SCCA and 23\% ( $N=182)$ AC/AS. There were no significant differences in RRs between histologic subgroups. The adjusted hazard ratio (HR) for death for SCCA vs AC/AS was $1.13(95 \% \mathrm{Cl} 0.93,1.38$ $P=0.23)$. When comparing SC/AS $(N=661,85 \%)$ to $A C$ alone $(N=120,15 \%)$, the adjusted HR for death was $1.23(95 \% \mathrm{Cl} 0.97$, $1.57, P=0.09$ ).

Conclusions: AC/AS and SCCA have similar survival in recurrent or metastatic cervical carcinoma when treated with chemotherapy doublets.

\footnotetext{
*Correspondence: Dr LG Seamon; E-mail: leigh.seamon@spectrumhealth.org

"Dr Harry J Long III is deceased.
}

Received 25 June 2017; revised 1 October 2017; accepted 12 October 2017; published online 28 November 2017

(C) 2018 Cancer Research UK. All rights reserved 0007-0920/18 
Cervical cancer remains a disease of epidemic proportions globally with 500000 new diagnoses each year worldwide and 250000 deaths (Jemal et al, 2011). Screening through cytology with and without high-risk human papillomavirus (HPV) DNA testing has significantly reduced the burden of disease in developed countries. The annual incidence and mortality rates in England are 2900 and 1000, respectively, while in the United States, the American Cancer Society estimates that there will be 12820 new cases and 4210 deaths in 2017 (Siegel et al, 2017). In Europe, cervical cancer is the sixth most common cancer among females, with nearly 55000 new cases diagnosed annually (Jemal et al, 2011). As a consequence of lack of universal screening, the poorest regions of the world (i.e., in Africa, Asia, and South America) are most deeply affected (Jemal et al, 2011).

Interestingly, the stratified squamous epithelium of the ectocervix and transformation zone lend themselves to cytologic sampling (i.e., Pap smear), allowing for the precursor of squamous cell carcinoma (SCCA), cervical intraepithelial neoplasia 3 (CIN3), to be readily identified and treated. This has resulted in a significant decrease in SCCA over the preceding three decades. However, glandular lesions (adenocarcinoma (AC) and adenosquamous (AS) carcinoma) harboured deeper within the canal are less easily detected and comprise $25 \%$ of newly diagnosed cases today (Smith et al, 2000; Young and Clement, 2002; Wang et al, 2004; Gien et al, 2010; Galic et al, 2012).

Despite distinct HPV aetiologic subtypes, genetic aberrations, and histologic features of SCCA and AC/AS, divergence of therapy is not predicated on histology. While early-stage, lymph nodenegative carcinomas of either histologic class (FIGO stage $\mathrm{I}_{-} \mathrm{IB}_{1}$ ) can be cleared by radical hysterectomy with lymphadenectomy, data are conflicting for locally advanced cervical AC/AS (FIGO stage $\mathrm{IB}_{2}$-IVA) in terms of susceptibility to eradication using conventional multimodality therapy (i.e., chemoradiation + brachytherapy). Relative radioresistance as evidenced by lower response rates (RRs), increased time to response and significantly decreased overall survival (OS) of AC/AS compared with SCCA has been reported previously (Katanyoo et al, 2012; Rose et al, 2014).

When considering recurrent or persistent disease that cannot be resected and metastatic cervical carcinoma (FIGO stage IVB), the prognostic impact of histology is more problematic as this is a population for which treatment is essentially palliative, with cures being remote and/or near impossible. Chemotherapy doublets (primarily platinum based) constituted the standard of care until 2013 when it was reported that based on a second interim analysis, Gynaecologic Oncology Group (GOG) protocol 240 met one of its primary end points. The incorporation of bevacizumab, an antiangiogenic drug, with either a cisplatin-paclitaxel or topotecan-paclitaxel chemotherapy backbone significantly improved OS by 3.7 months (hazard ratio (HR) 0.71 ; 97\% CI: $0.54,0.94 ; P=0.0035$ ) (Tewari et al, 2014). The integration of antiangiogenesis therapy in this high risk poor prognostic population also led to statistically significant improvements in progression-free survival (PFS) and RR (Tewari et al, 2014). According to analyses of patient-reported outcomes using three previously validated instruments, these clinical benefits were not accompanied by a significant deterioration in health-related quality of life (Penson et al, 2015).

The GOG 240 results led first to United Kingdom Cancer Drug Fund approval of bevacizumab for women in England with advanced cervical cancer on 5 March 2014, and then to US FDA approval of both bevacizumab-containing triplet regimens on 14 August 2014. This was followed by Swissmedic approval of bevacizumab for cervical cancer on 22 December 2014, a Positive Opinion of GOG 240 issued by the Committee for Medicinal Products for Human Use on 27 February 2015, and finally European Medicines Agency approval for the European Union on
8 April 2015. Recently, the results of the protocol-specified analysis of OS confirmed a statistically significant survival benefit conferred by bevacizumab with extended follow-up (Tewari et al, 2017).

As a tertiary objective, GOG 240 prospectively validated the use of the Moore scoring criteria based on pooled clinical factors identified in prior phase III randomised trials led by the GOG in this patient population (Moore et al, 2010; Tewari et al, 2015). Importantly, tumour histology is not included in the Moore criteria, and in an analysis of GOG 240 prognostic factors, the benefit conferred by bevacizumab was not detected in AC/AS (Tewari et al, 2014). However, these histologies were found in only $27 \%$ of the study population and therefore GOG 240 was underpowered to draw any definitive conclusions concerning efficacy or lack thereof in AC/AS.

These observations led to two important questions. Specifically, does the difference in prognosis between SCCA and AC/AS previously reported in various studies of early-stage tumours and locally advanced disease apply to women struggling with advanced (i.e., recurrent or metastatic) disease? In other words, is survival following treatment with chemotherapy doublets different for SCCA and AC/AS? A second question was whether bevacizumab should be offered to women with AC/AS given the potential for improved OS despite the apparent lack of efficacy in GOG protocol 240 (underpowered for AC/AS) and known side effect profile of the drug (e.g., $8.6 \%$ fistula). While there was no clear way to directly address the second question, we approached the first question by increasing the sample size of advanced AC/AS to test our hypothesis that the behaviour of these histologic entities (i.e., SCCA vs AC/AS) in terms of survival parameters governing systemic therapy comprised of chemotherapy doublets would not differ.

\section{MATERIALS AND METHODS}

Cases were pooled from GOG phase III randomised trials in recurrent or persistent and metastatic cervical carcinoma, which permitted enrolment of patients with AC/AS histology. Each study was approved by the National Cancer Institute Central Institutional Review Board as well as the individual participating institutional local review boards and every patient provided written consent to these trials (Long et al, 2005; Monk et al, 2009; Tewari et al, 2014). This ancillary data study was approved by the GOG.

Eligibility. Patients with histologically confirmed advanced (stage IVB), recurrent, or persistent SCCA, AC, and AS carcinomas of the uterine cervix enrolled in the GOG Protocols 0179 (combination arm only), 0204 (all arms), and 0240 (non-bevacizumab arms) were included in this ancillary analysis of patients treated with platinum-based and non-platinum-based chemotherapy doublets. Patients receiving bevacizumab and those treated with single-agent cisplatin were excluded for purposes of this analysis, which was designed to evaluate survival of SCCA and AC/AS following treatment with chemotherapy doublets only.

The trial eligibility and exclusions for these three protocols have been previously reported (Long et al, 2005; Monk et al, 2009; Tewari et al, 2014). In brief, inclusion criteria were limited to stage IVB, recurrent or persistent cervical carcinoma with measurable disease and a performance status of 0,1 (GOG 0204, 240) or 0, 1, or 2 (0179). Patients with previous chemotherapy for recurrence, concurrent or past malignancy, bilateral hydronephrosis unresolved with ureteral stents or percutaneous nephrostomy, and craniospinal metastatic disease were ineligible. All patients had to have measureable disease and all cases underwent GOG Pathology Committee review to assign histology. 
Table 1. Clinical characteristics and response rates for the primary objective (SC vs AC + AS) and for the secondary objective (SC + AS vs AC)

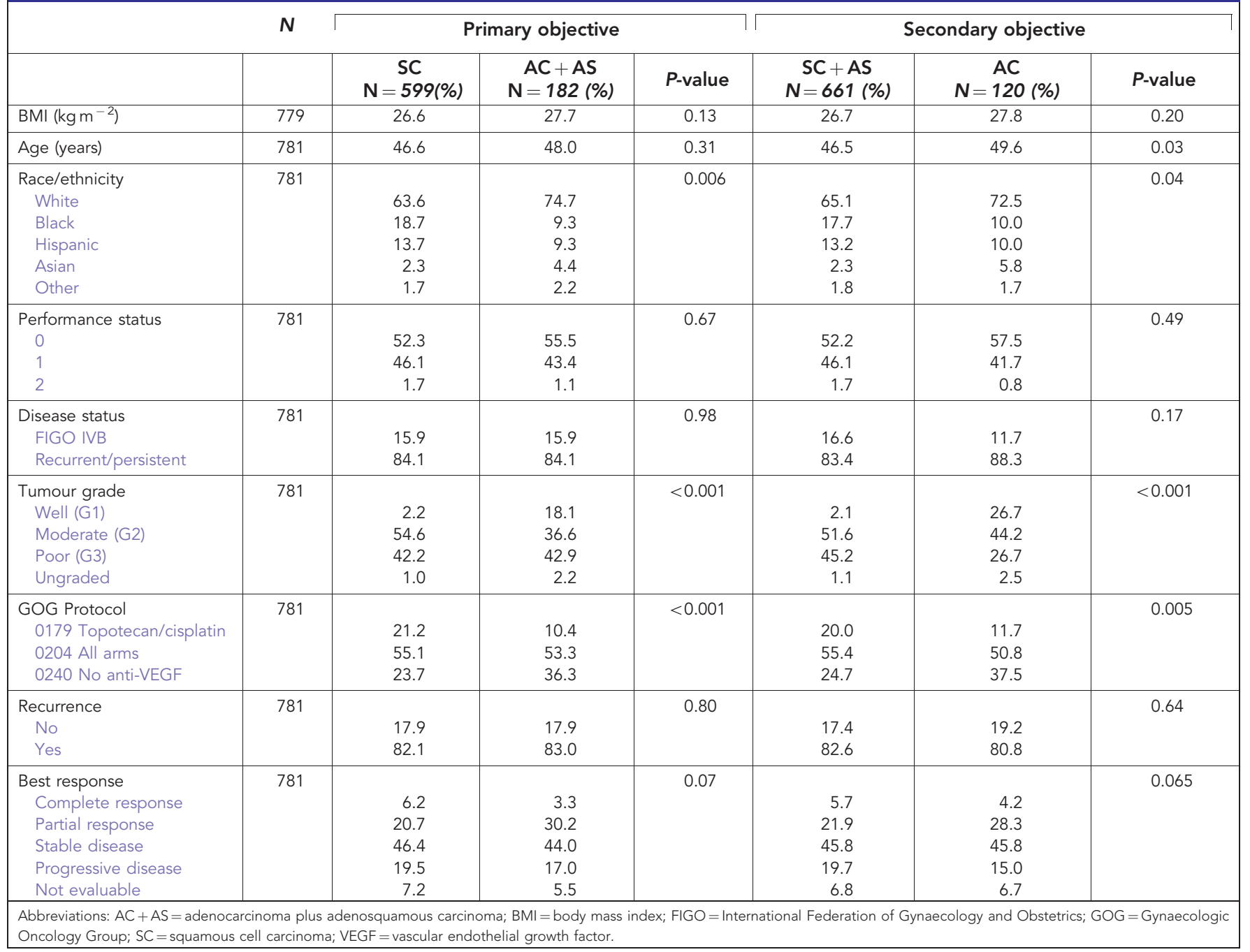

Treatment. While chemotherapy administration on the GOG 0179 combination arm included topotecan $0.75 \mathrm{mg} \mathrm{m}^{-2}$ intravenously on days 1,2 , and 3 , followed by cisplatin $50 \mathrm{mg} \mathrm{m}^{-2}$ on day 1 every 3 weeks (Long et al, 2005), GOG 0204 was a trial of four cisplatin-containing doublet combinations (Monk et al, 2009). Patients on GOG 0204 received one of the following: paclitaxel $135 \mathrm{mg} \mathrm{m}^{-2}$ over 24 hours on day 1 and cisplatin $50 \mathrm{mg} \mathrm{m}^{-2}$ on day 2 every 3 weeks; vinorelbine $30 \mathrm{mg} \mathrm{m}^{-2}$ on days 1 and $8+$ cisplatin $50 \mathrm{mg} \mathrm{m}^{-2}$ on day 1 every 3 weeks; gemcitabine $1000 \mathrm{mg} \mathrm{m}^{-2}$ on days 1 and $8+$ cisplatin $50 \mathrm{mg} \mathrm{m}^{-2}$ on day 1 every 3 weeks; or topotecan $0.75 \mathrm{mg} \mathrm{m}^{-2}$ intravenously on days 1 , 2 , and 3 , followed by cisplatin $50 \mathrm{mg} \mathrm{m}^{-2}$ on day 1 every 3 weeks (Monk et al, 2009).

Gynaecologic Oncology Group 0240 was a phase III trial of the incorporation of bevacizumab in advanced cervical cancer. As stated above, for purposes of our analysis, we included only the non-bevacizumab arms of this trial. Thus, patients received one of the following regimens: paclitaxel 135 or $175 \mathrm{mg} \mathrm{m}^{-2}+$ cisplatin $50 \mathrm{mg} \mathrm{m}^{-2}$ or paclitaxel $175 \mathrm{mg} \mathrm{m}^{-2}$ on day 1 and topotecan $0.75 \mathrm{mg} \mathrm{m}^{-2}$ intravenously days 1,2 , and 3 (Tewari et al, 2014).

Statistical considerations. The data abstracted included patient demographics, clinicopathologic features, chemotherapy regimens, and survival outcomes. Binary exchange analysis was performed to estimate OS and PFS for the primary objective comparing SCCA cases to all glandular cases, and for the secondary objective in which all squamous-containing histology (SCCA + AS) cases were compared with AC alone. An exploratory analysis was also undertaken to determine differences in survival of AC vs AS carcinoma.

Categorical variables were compared among the histology groups by the Pearson's $\chi^{2}$ test and continuous variables by the Kruskal-Wallis test (Pearson, 1900; Kruskal and Wallis, 1952). Survival was estimated using the Kaplan-Meier method (Kaplan and Meier, 1958). The Cox proportional hazards model was used to evaluate independent prognostic factors (body mass index, age, race/ethnicity, performance status, disease status, and tumour grade) and to estimate their covariate-adjusted effects on PFS and OS (Cox, 1972). A correction for multiplicity of comparisons was made and nonlinearity of the effect of continuous variables was assessed using restricted cubic splines (Molinari et al, 2001). All statistical tests were two-tailed with the significance level set at $\alpha=0.05$. We estimated from the known histologic distribution in the three studies that we would have roughly $80 \%$ power to detect a $20 \%$ difference in the hazard of death between different histologic groups in the primary objective. Statistical analyses were performed using the $\mathrm{R}$ programming language and environment ( $\mathrm{R}$ Core Team, 2013). 
A

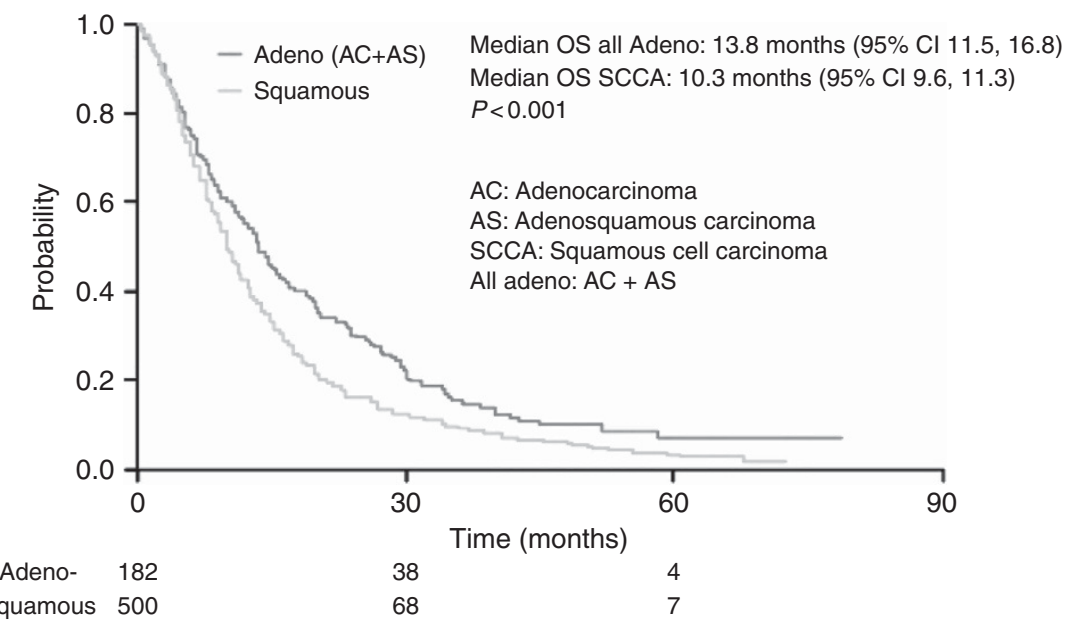

B

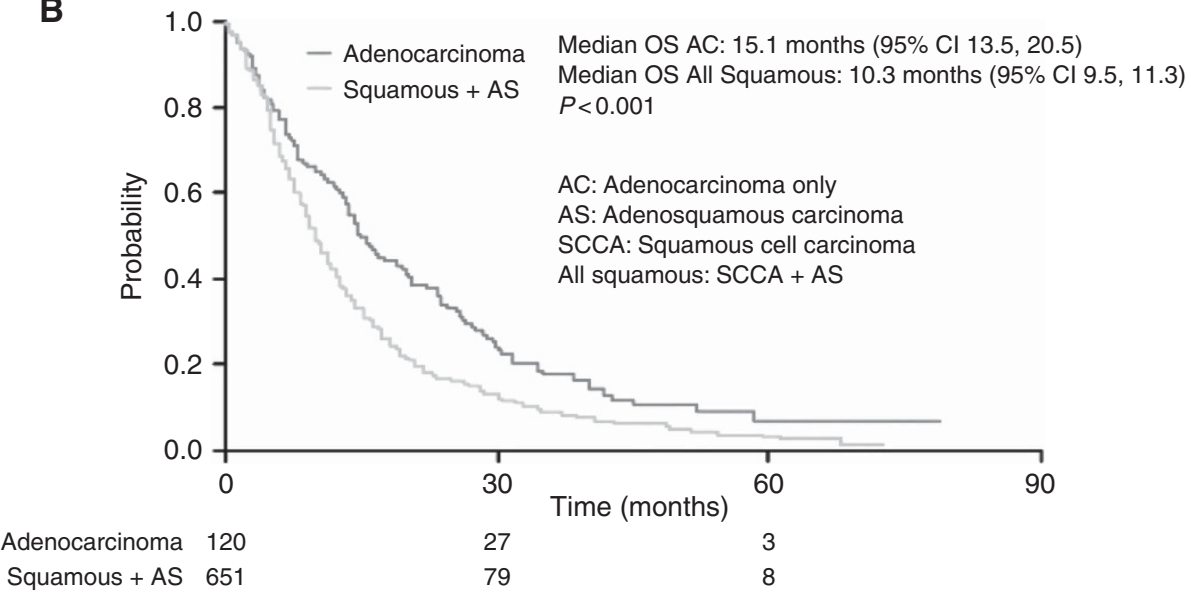

Figure 1. Kaplan-Meier curves of overall survival. (A) Primary objective (SCCA vs AC +AS carcinoma) and (B) secondary objective (SCCA + AS vs $\mathrm{AC})$.

\section{RESULTS}

Seven hundred and eighty-one patients from GOG 0179, 0204, and 0240 met the inclusion criteria. Approximately $77 \%(n=599)$ had SCCA, while the remaining $23 \%$ of patients $(n=182)$ had AC or AS carcinoma. The similarity of SCCA compared to all AC or AS patients regarding clinical-pathological characteristics, recurrence, and RRs are summarised in Table 1.

The median PFS for the SCCA patients compared to the AC+ AS groups is 4.8 months (95\% CI: 4.6, 5.3 months) vs 5.7 months (95\% CI: 4.8, 7.1 months), $P=0.27$, respectively, while the median OS is 10.3 months (95\% CI: 9.6, 11.3 months) vs 13.8 months (95\% CI: $11.5,16.8$ months), $P<0.001$. The Kaplan-Meier curve for OS appears in Figure 1A.

Although on univariate analysis it appears that patients with glandular cancers experienced significantly improved OS compared to those with SCCA, this effect disappeared on multivariate analysis when the comparison is adjusted by other factors. Cox proportional hazards modelling demonstrates that SCCA had similar survival compared to AC or AS. While the adjusted hazard ratio (aHR) for disease progression in SCCA patients was 0.93 (95\% CI: $0.77,1.12, P=0.43$ ), the adjusted HR for death in SCCA patients was $1.13(95 \%$ CI: $0.93,1.38, \quad P=0.23)$. The Supplementary Table depicts the multivariate analysis for multiple prognostic factors.

In the secondary objective, all squamous cell-containing histology (SCCA and AS, $N=661 ; 85 \%$ ) were compared to AC alone $(N=120 ; 15 \%)$. The clinical-pathological characteristics, recurrence, and RRs are also summarised in Table 1. The KaplanMeier curve for OS appears in Figure 1B. Similar to what was observed with our primary objective, the binary exchange analysis combining SCCA and AS did not show significant improvement in OS compared to AC alone on multivariate analysis (HR death 1.23, $95 \% \mathrm{CI}: 0.97,1.57, P=0.093)$. The multivariate analysis of multiple prognostic factors also appears in the Supplementary Table.

Finally, we explored OS in patients with AC $(N=120 ; 66 \%)$ and compared them to those with AS $(N=62 ; 34 \%)$. The median PFS for the AC and AS groups is 6.4 months (95\% CI: 5.2, 8.0) and 4.4 months (95\% CI: 3.9, 6.4), respectively, log-rank test $\mathrm{P}=0.06$. The median OS for the AC and AS groups is 15.1 months (95\% CI: $13.5,20.5)$ and 10.1 months (95\% CI: 8.5, 15.2), respectively, logrank test, $\mathrm{P}=0.09$. On multivariate analysis, there was also no difference in survival (aHR death 1.19, 95\% CI: 0.81, 1.74, $P=0.38$ ).

\section{DISCUSSION}

Although the impact of histology on survival in recurrent or persistent and metastatic (stage IVB) cervical cancer has not been previously addressed in the literature, our analyses suggest that response to systemic therapy and survival rates following treatment with chemotherapy doublets in this population are not different for SCCA and AC/AS carcinoma. Furthermore, when 'squamous' tumours were combined (i.e., SCCA + AS) and compared with 

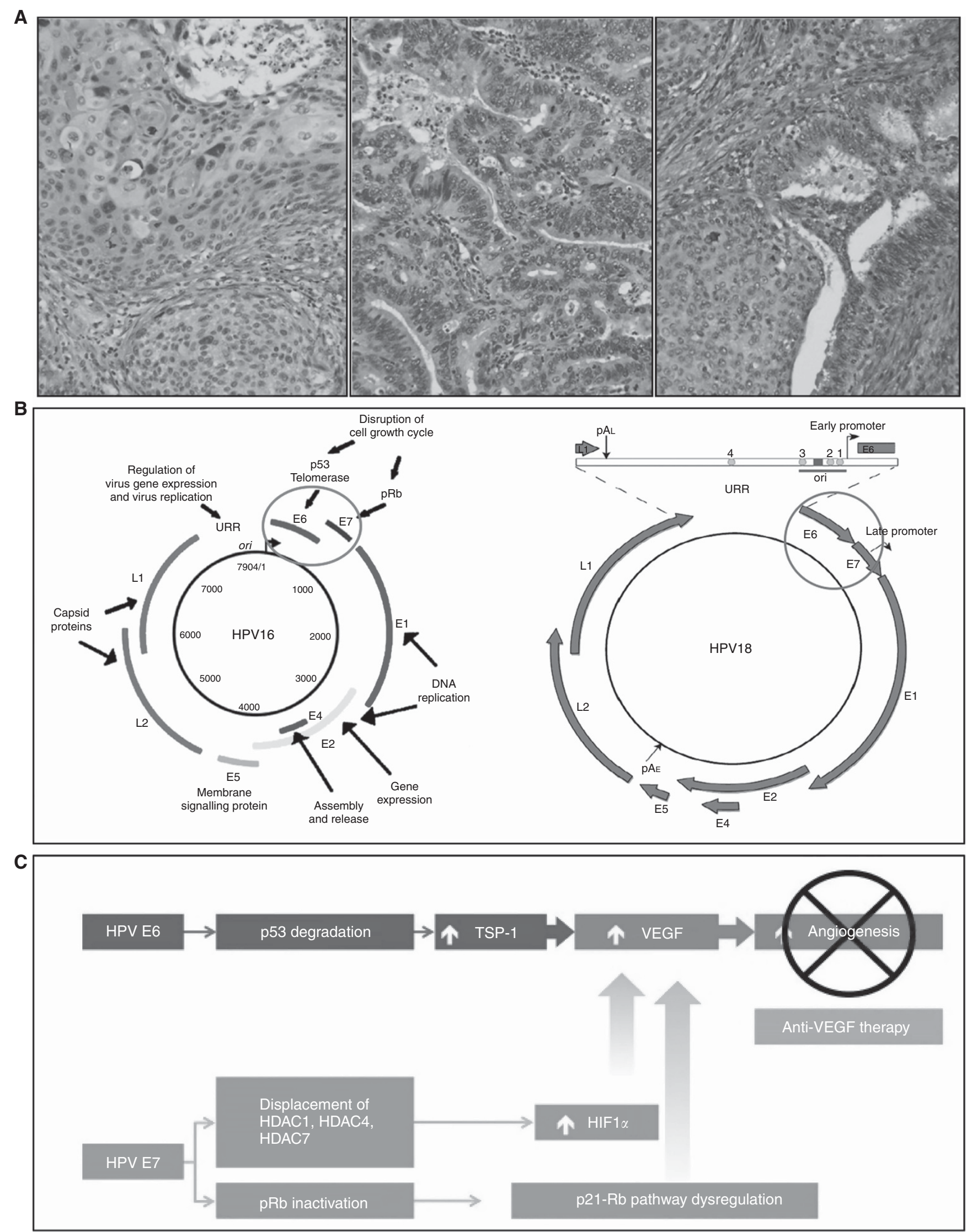

Figure 2. Squamous cell carcinoma vs AC vs AS of the uterine cervix: different diseases? (A) Histologic appearance of SCCA (left), AC (centre), and AS (right). (B) Human papillomavirus 16 genome (left) and HPV 18 genome (right). (C) Proposed molecular cascade through which tumour hypoxia and HPV oncogenes E6 and E7 drive angiogenesis. 
Table 2. Molecular aberrations between SCCAs and ACs of the uterine cervix

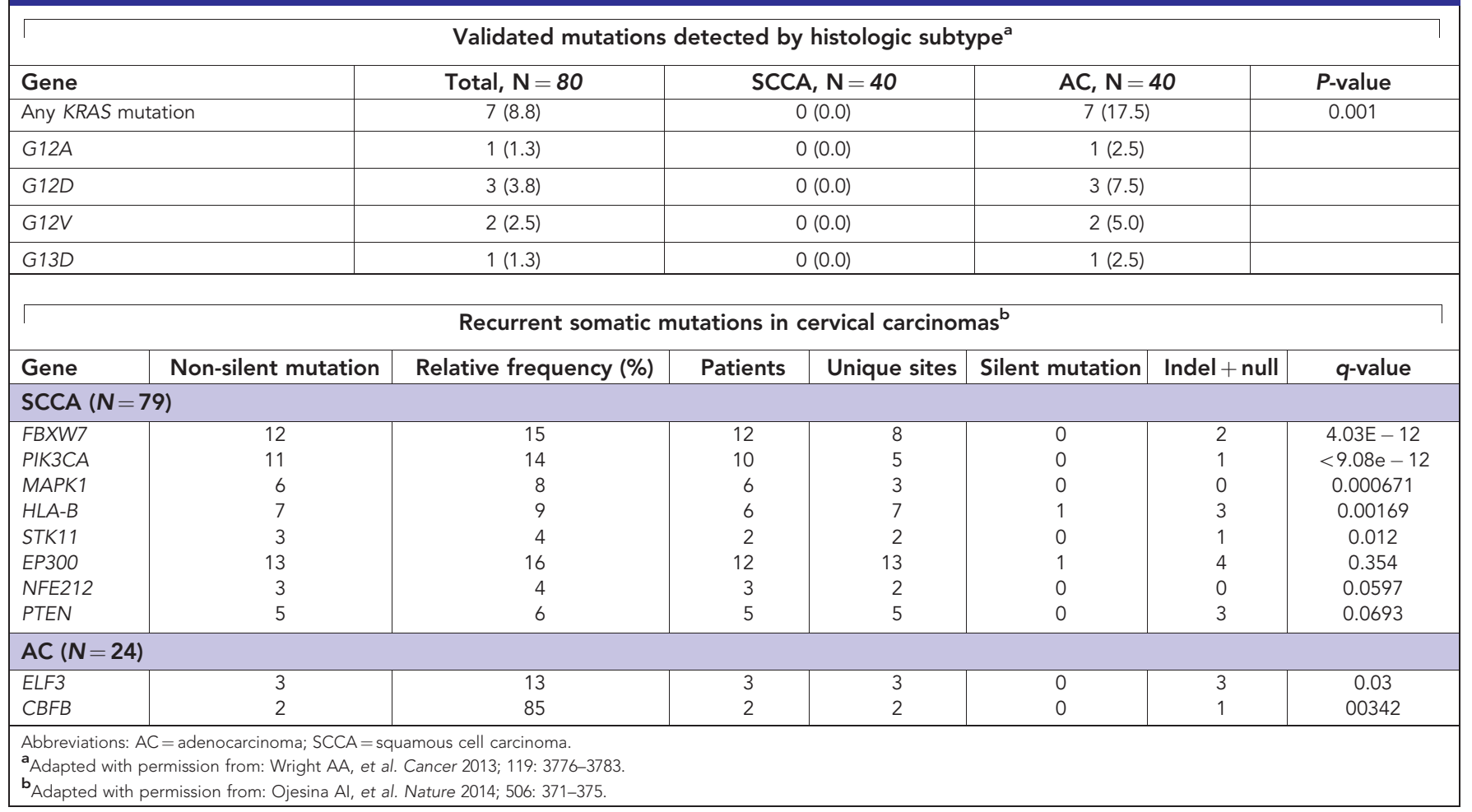

pure glandular lesions (i.e., AC), survival was not significantly different. Finally, our study suggests that advanced cervical AC behaves clinically analogous to advanced cervical AS when treated with chemotherapy doublets.

Molecular, pathologic, and some clinical evidence, however, supports the contention that despite having many shared risk factors, including high-risk HPV infection (Silcocks et al, 1987; Green et al, 2003; Berrington de Gonzalez et al, 2004), AC/AS and SCCA of the cervix are two different diseases (Figure 2A). There appears to be a higher prevalence of HPV subtype 18 infection in AC compared with SCCA (Figure 2B) (Fujiwara et al, 2014). In addition, the development of SCCA appears to be driven primarily by HPV 16 and a wider diversity of the relatively uncommon oncogenic HPV subtypes (Figure 2B). Of particular relevance is that both HPV 16 and 18 genomes contain the E6 and E7 oncogenes, which have downstream effects on a final common pathway towards virally mediated tumour angiogenesis (Figure 2C). Other epidemiologic differences include smoking (strongly implicated in SCCA $v s$ AC) as well as nulliparity and obesity (more commonly seen in ACs) (Fujiwara et al, 2014).

A systematic molecular analysis of cervical cancers has shown that ACs $(n=40)$ have distinct oncogenic mutations compared to SCCA $(n=40)$ (Table 2) (Wright et al, 2013). In particular, KRAS mutations are observed only in ACs (17.5 AC vs 0\% SCCA, $P=0.01$ ) and EGFR mutations are not detected (0 AC vs $7.5 \%$ SCCA, $P=0.24)$. In another report, the molecular profiles of 79 SCCA and 24 ACs were considered (Table 2) (Ojesina et al, 2014). In addition to uncovering new genomic alterations in SCCA (E1A binding protein $p 300, F-b o x$ and WD repeat domain containing 7 , major histocompatibility complex, class $I, B$, mitogen-activated protein kinase 1, nuclear factor, erythroid 2-like 2), two genes with somatic mutations observed only in ACs were identified, E74-like factor 3 and core-binding factor, $\beta$-subunit at a frequency of $13 \%$ and $8 \%$, respectively.

The molecular data reviewed above further highlight differences between AC and SCCA and suggests possibly new targets for combating cervical cancer. However, before our current analyses, it was unknown if histologic subtype impacts clinical outcomes following chemotherapy treatment for recurrent or persistent or metastatic disease. The pooled data of three large phase III randomised trials in this high-risk cervical cancer population were obtained from the reliable, prospectively maintained GOG database. The analyses are unique as such a large cohort of AC/AS is not likely to be obtainable anywhere else in the world. Accordingly, given that the existing literature on tumour histology as an independent prognostic factor in cervical cancer has focused on early-stage and locally advanced disease, our study fills an important void that some investigators would be surprised to find still exists despite years of study.

Based on subsequent studies by the GOG, including the phase II trial of bevacizumab monotherapy in which single agent activity in heavily pre-treated, recurrent cervical cancer was reported (GOG 227C; Monk et al, 2009) and the previously discussed randomised phase III trial of chemotherapy doublets with and without bevacizumab (GOG 240; Tewari et al, 2014), the standard of care for advanced cervical cancer has shifted from chemotherapy doublets alone to chemotherapy doublets + bevacizumab. In point of fact, both triplet regimens studied in GOG 240 (i.e., cisplatinpaclitaxel-bevacizumab and topotecan-paclitaxel-bevacizumab) are listed as Category 1 in the National Comprehensive Cancer Network Cervical Cancer Treatment Guidelines. In GOG 240 the survival impact conferred by bevacizumab was not observed in AC, either due to underpowering of $\mathrm{AC}$ cases or reduced activity of bevacizumab in cervical AC or both. The question on the table is whether anti-vascular endothelial growth factor (VEGF) therapy can improve survival in women with advanced cervical AC/AS. Although our analyses suggest that SCCA and AC/AS behave similarly when treated with chemotherapy doublets, it is not possible from these data to infer any equivalence of activity of antiangiogenesis therapy between advanced cervical SCCA and AC/AS. 
Table 3. Activity of bevacizumab in non-cervix adenocarcinoma

\begin{tabular}{|c|c|c|c|c|}
\hline Author & Disease & Regimens & PFS & OS \\
\hline Hurwitz et al & $\begin{array}{l}\text { Colorectal } \\
\text { ECOG PS 0-1 } \\
\text { First line } \\
\text { Metastatic }\end{array}$ & $\begin{array}{l}\text { ILF }+ \text { placebo } \\
\text { ILF }+ \text { Bev }\end{array}$ & $\begin{array}{l}6.2 \mathrm{~m} \\
10.6 \mathrm{~m} \\
\text { HR } 0.54 ; 95 \% \mathrm{Cl}: 0.45,0.66\end{array}$ & $\begin{array}{l}15.2 \mathrm{~m} \\
23.8 \mathrm{~m} \\
\mathrm{HR} 0.66 ; 95 \% \mathrm{Cl}: 0.54,0.81\end{array}$ \\
\hline Sandler et al & $\begin{array}{l}\text { Non-SCCA } \\
\text { NSCLC } \\
\text { ECOG PS 0-1 } \\
\text { First line, met } \\
\text { Loc adv, recur }\end{array}$ & $\begin{array}{l}\text { Carb/Pac }+ \text { placebo } \\
\text { Carb/Pac }+ \text { Bev }\end{array}$ & $\begin{array}{l}4.8 \mathrm{~m} \\
6.4 \mathrm{~m} \\
\mathrm{HR} 0.65 ; 95 \% \mathrm{Cl}: 0.56,0.76\end{array}$ & $\begin{array}{l}10.3 \mathrm{~m} \\
12.3 \mathrm{~m} \\
\mathrm{HR} 0.80 ; 95 \% \mathrm{Cl}: 0.69,0.93\end{array}$ \\
\hline Miller et al & $\begin{array}{l}\text { Breast } \\
\text { ECOG PS 0-1 } \\
\text { Loc recur, met }\end{array}$ & $\begin{array}{l}\text { Pac }+ \text { placebo } \\
\text { Pac }+ \text { Bev }\end{array}$ & $\begin{array}{l}5.8 \mathrm{~m} \\
11.4 \mathrm{~m} \\
\mathrm{HR} 0.42 ; 95 \% \mathrm{Cl}: 0.34,0.52\end{array}$ & $\begin{array}{l}24.8 \mathrm{~m} \\
26.5 \mathrm{~m} \\
\text { HR } 0.87 ; 95 \% \mathrm{Cl}: 0.72,1.05\end{array}$ \\
\hline Burger et al & $\begin{array}{l}\text { Ovary } \\
\text { GOG PS 0-2 } \\
\text { First line } \\
\text { FIGO stage III/IV }\end{array}$ & $\begin{array}{l}\mathrm{CP}+\text { placebo }- \text { placebo } \\
\mathrm{CP}+\mathrm{Bev}-\text { placebo } \\
\mathrm{CP}+\mathrm{Bev}-\mathrm{Bev}\end{array}$ & $\begin{array}{l}10.3 \mathrm{~m} \\
\\
11.2 \mathrm{~m} \\
14.1 \mathrm{~m} \\
\mathrm{HR} 0.717 ; 95 \% \mathrm{Cl}: 0.63,0.82\end{array}$ & $\begin{array}{l}39.3 \mathrm{~m} \\
\\
38.7 \mathrm{~m} \\
39.7 \mathrm{~m} \\
\mathrm{HR} 0.915 ; 95 \% \mathrm{Cl}: 0.73,1.15\end{array}$ \\
\hline
\end{tabular}

These data do allow for some speculation concerning the incorporation of antiangiogenesis therapy for advanced cervical AC/AS. Not only are RRs and survival similar between advanced cervical SCCA and AC/AS treated with systemic therapy (specifically, chemotherapy doublets), but the molecular aberrations in predominantly HPV16-driven cervical SCCA and the predominantly HPV 18-induced cervical AC/AS both favour a proangiogenic tumour environment. Although the biologic rationale for targeting the VEGF-dependent angiogenesis pathway in cervical cancer is complex, a mechanistic rationale has been proposed (Eskander and Tewari, 2014). The HPV E6 and E7 oncogenes affect downstream angiogenic pathways. E6 mediates p53 degradation with subsequent increase in thrombospondin-1 leading to increase in VEGF and thus promotion of angiogenesis (Figure 2C). Human papillomavirus E7 inactivates pRb causing $\mathrm{p} 21-\mathrm{Rb}$ pathway dysregulation triggering VEGF production. Additionally, E7 displaces HDAC1 (histone deacetylase), HDAC4, and HDAC7 initiating a cascade that increases hypoxia-inducible factor $1 \alpha$ (Figure 2C). A rationale that cervical SCCA and AC/AS will have a similar response to VEGF inhibition is supported by both tumour histologies being driven by viral E6/E7 with induction of the VEGF-dependent tumour angiogenesis.

Tumours of similar histology arising in different organs appear to respond to similar therapy. Examples of this phenomenon are found in the response of malignant germ cell tumours of the testis and ovary to the bleomycin-etoposide-cisplatin regimen (Mann et $a l, 1989)$ as well as the reported efficacy of the cisplatinetoposide doublet in small-cell carcinoma of the lung and cervix (Hoskins et al, 2003). In point of fact, the demonstrable activity of bevacizumab in other ACs including colorectal, lung, breast, and ovarian cancer provides support for consideration of bevacizumab efficacy in AC of the cervix (Table 3) (Hurwitz et al, 2004; Sandler et al, 2006; Miller et al, 2007; Burger et al, 2011). It is noteworthy that because of concerns for catastrophic pulmonary haemorrhage associated with centrally located SCCA lung tumours, bevacizumab is only approved by the US FDA for ACs of the lung.
It should be emphasised that our data concerning the response and survival associated with chemotherapy doublets has not been prospectively validated. Given the relative infrequency of glandular tumours of the cervix and the change in standard of care from chemotherapy doublets to bevacizumab-containing triplet therapy, a clinical trial to answer this question may not be feasible. Ultimately, the emergence of validated predictive biomarkers for targeted therapy will determine whether SCCA and AC/AS should be treated with different drugs, particularly those that may be governed by SCCA- and/or AC/AS-specific mutations. In this regard, treatment algorithms for SCCA and AC/AS are likely to diverge. However, given the wide net cast by antiangiogenesis therapy, including its activity in the tumour microenvironment, until distinct histologic-driven therapies emerge, patients with recurrent or persistent and metastatic cervical AC/AS should be counselled regarding the known toxicities of anti-VEGF therapy and lack of proven efficacy against AC of the cervix, balanced with the potential benefits, which may include a significant survival advantage.

\section{ACKNOWLEDGEMENTS}

The following GOG member institutions participated in the primary treatment studies: Roswell Park Cancer Institute, University of Alabama at Birmingham, Duke University Medical Center, Abington Memorial Hospital, Walter Reed Army Medical Center, Wayne State University, University of Minnesota Medical School, Northwestern Memorial Hospital, University of Mississippi Medical Center, Colorado Gynaecologic Oncology Group PC, University of Washington, University of Pennsylvania Cancer Center, Milton S Hershey Medical Center, University of Cincinnati, University of North Carolina School of Medicine, University of Iowa Hospitals and Clinics, University of Texas Southwestern Medical Center at Dallas, Indiana University School of Medicine, Wake Forest University School of Medicine, University of 
California Medical Center at Irvine, Rush-Presbyterian-St Luke's Medical Center, Magee Women's Hospital, SUNY Downstate Medical Center, University of Kentucky, University of New Mexico, The Cleveland Clinic Foundation, State University of New York at Stony Brook, Washington University School of Medicine, Memorial Sloan-Kettering Cancer Center, Cooper Hospital/University Medical Center, Columbus Cancer Council, MD Anderson Cancer Center, University of Massachusetts Medical School, Fox Chase Cancer Center, Women's Cancer Center, University of Oklahoma, University of Virginia Health Sciences Center, University of Chicago, Mayo Clinic, Case Western Reserve University, Tampa Bay Cancer Consortium, Yale University, University of Wisconsin Hospital, Cancer Trials Support Unit, University of Texas-Galveston, Women and Infants Hospital, The Hospital of Central Connecticut, Georgia Core, Aurora Women's Pavilion of West Allis Memorial Hospital, Grupo Espanol de Investigacion en Cancer de Ovario, University of California, San Francisco-Mt Zion, St Joseph's Hospital and Medical Center (Arizona), and Community Clinical Oncology Program.

\section{CONFLICT OF INTEREST}

All the authors cite no relevant conflicts of interest related to this manuscript, except as noted below: $\operatorname{Dr}(\mathrm{s})$ Tewari (study chair/ principal investigator for GOG 240), Penson (quality of life chair for GOG 240), Oaknin (Spain chair through GEICO for GOG 240), and Monk (senior author of GOG 240 and chair of the Cervix Cancer Committee of the NRG Oncology Cooperative Group and co-chair of the Gynaecologic Cancer Intergroup) were members of the scientific steering committee that conducted GOG 240. To participate in the regulatory discussions through which bevacizumab could potentially be approved for women struggling with advanced cervical cancer, these authors as well as author Eisenhauer participated on 1-2 advisory boards held by Roche/ Genentech. Monk, Penson, and Tewari subsequently joined the Roche/Genentech speaker's bureau to help review appropriate patient selection and management of bevacizumab-related adverse events with the oncology community. The institutions where Monk, Oaknin, and Tewari practice have contracted research grants with Roche/Genentech to conduct trials evaluating the antiPD-L1 agent, atezolizumab. Roche/Genentech contracted research with institution: Monk, Oaknin, Tewari; Roche/Genentech Advisory Boards participation: Monk, Penson, Eisehauer, Tewari; Roche/Genentech Speaker's Bureau: Monk, Penson, Tewari.

\section{REFERENCES}

Berrington de Gonzalez A, Sweetland S, Green J (2004) Comparison of risk factors for squamous cell and adenocarcinomas of the cervix: a metaanalysis. Br J Cancer 90(9): 1787-1791.

Burger RA, Brady MF, Bookman MA, Fleming GF, Monk BJ, Huang H, Mannel RS, Homesley HD, Fowler J, Greer BE, Boente M, Birrer MJ, Liang SX (2011) Incorporation of bevacizumab in the primary treatment of ovarian cancer. N Engl J Med 365(26): 2473-2483.

Cox DR (1972) Regression models and life-tables. J R Stat Soc Ser B 34(2): $187-220$.

Eskander RN, Tewari KS (2014) Targeting angiogenesis in advanced cervical cancer. Ther Adv Med Oncol 6(6): 280-292.

Fujiwara K, Monk B, Devouassoux-Shisheboran M (2014) Adenocarcinoma of the uterine cervix: Why is it different? Curr Oncol Rep 16(12): 416.

Galic V, Herzog TJ, Lewin SN, Neuqut A, Burke WM, Lu YS, Hershman DL, Wright JD (2012) Prognostic significance of adenocarcinoma histology in women with cervical cancer. Gynecol Oncol 125(2): 287-291.

Gien LT, Beauchemin MC, Thomas G (2010) Adenocarinoma: a unique cervical cancer. Gynecol Oncol 116(1): 140-146.
Green J, Berrington de Gonzalez A, Sweetland S, Beral V, Chilvers C, Crossley B, Deacon J, Hermon C, Jha P, Mant D, Peto J, Pike M, Vessey MP (2003) Risk factors for adenocarcinoma and squamous cell carcinoma of the cervix in women aged 20-44 years: the UK National Case-Control Study of Cervical Cancer. Br J Cancer 89(11): 2078-2086.

Hoskins PJ, Swenerton KD, Pike JA, Lim P, Aquino-Parsons C, Wong F, Lee N (2003) Small-cell carcinoma of the cervix: fourteen years of experience at a single institution using a combined-modality regimen of involved-field irradiationand platinum-based combination chemotherapy. J Clin Oncol 21(18): 3495-3501.

Hurwitz H, Fehrenbacher L, Novotny W, Cartwright T, Hainsworth J, Heim W, Berlin J, Baron A, Griffing S, Holmgren E, Ferrara N, Fyfe G, Rogers B, Ross R, Kabbinavar F (2004) Bevacizumab plus irinotecan, fluorouracil, and leucovorin for metastatic colorectal cancer. N Engl J Med 350(23): 2335-2342.

Jemal A, Bray F, Center MM, Ferlay J, Ward E, Forman D (2011) Global Cancer Statistics. CA Cancer J Clin 61(2): 69-90.

Kaplan EL, Meier P (1958) Nonparametric estimation from incomplete observations. J Am Stat Assoc 53(282): 457-481.

Katanyoo K, Sanguanrungsirikul S, Manusirivithaya S (2012) Comparision of treatement outcomes between squamous cell carcinoma and adenocarcinoma in locally advanced cervical cancer. Gynecol Oncol 125(2): 292-296.

Kruskal WH, Wallis WA (1952) Use of ranks in one-criterion variance analysis. J Am Stat Assoc 47(260): 583-621.

Long HJ, Bundy FN, Grendys Jr EC, Benda JA, McMeekin DS, Sorosky J, Miller DS, Eaton LA, Fiorica JV (2005) Randomized phase III trial of cisplatin with or without toptecan in carcinoma of the uterine cervix: a Gynecologic Oncology Group study. J Clin Oncol 23(21): 4626-4633.

Mann JR, Pearson D, Barrett A, Raafat F, Barnes JM, Wallendszus KR (1989) Results of the United Kingdom Children's Cancer Study Group's malignant germ cell tumor studies. Cancer 63(9): 1657-1667.

Miller K, Wang M, Gralow J, Dickler M, Cobleigh M, Perez EA, Shenkier T, Cella D, Davidson NE (2007) Paclitaxel plus bevacizumab versus paclitaxel alone for metastatic breast cancer. N Engl J Med 357(26): 2666-2676.

Molinari N, Daures JP, Durand JF (2001) Regression splines for threshold selection in survival data analysis. Stat Med 20(2): 237-247.

Monk BJ, Sill MW, Burger RA, Gray HJ, Buekers TE, Roman LD (2009) Phase II trial of bevacizumab in the treatment of persistent or recurrent squamous cell carcinoma of the cervix: a Gynecologic Oncology Group study. J Clin Oncol 27: 1069-1074.

Monk BJ, Sill MW, McMeekin DS, Cohn DE, Ramondetta LM, Boardman CH, Benda J, Cella D (2009) Phase III trial of four cisplatincontaining doublet combinations in stage IVB, recurrent, or persistent cervical carcinoma: a Gynecologic Oncology Group study. J Clin Oncol 27(28): 4649-4655.

Moore DH, Tian C, Monk BJ, Long HJ, Omura GA, Bloss JD (2010) Prognostic factors for response to cisplatin-based chemotherapy in advanced cervical carcinoma: a Gynecologic Oncology Group Study. Gynecol Oncol 116(1): 44-49.

Ojesina AI, Lichtenstein L, Freeman SS, Pedamallu CS, Imaz-Rosshandler I, Pugh TJ, Cherniack AD, Ambrogio L, Cibulskis K, Bertelsen B, Romero-Cordoba S, Treviño V, Vazquez-Santillan K, Guadarrama AS, Wright AA, Rosenberg MW, Duke F, Kaplan B, Wang R, Nickerson E, Walline HM, Lawrence MS, Stewart C, Carter SL, McKenna A, RodriguezSanchez IP, Espinosa-Castilla M, Woie K, Bjorge L, Wik E, Halle MK, Hoivik EA, Krakstad C, Gabiño NB, Gómez-Macías GS, Valdez-Chapa LD, Garza-Rodríguez ML, Maytorena G, Vazquez J, Rodea C, Cravioto A, Cortes ML, Greulich H, Crum CP, Neuberg DS, Hidalgo-Miranda A, Escareno CR, Akslen LA, Carey TE, Vintermyr OK, Gabri el SB, Barrera-Saldaña HA, Melendez-Zajgla J, Getz G, Salvesen HB, Meyerson M (2014) Landscape of genomic alterations in cervical carcinomas. Nature 506(7488): 371-377.

Pearson K (1900) On the criterion that a given system of deviations from the probable in the case of correlated system of variables is such that it can be reasonably supposed to have arisen form random sampling. Philos Mag Ser 5 50(302): 157-175.

Penson RT, Huang HQ, Wenzel LB, Monk BJ, Stockman S, Long III HJ, Ramondetta LM, Landrum LM, Oaknin A, Reid TJ, Leitao MM, Method M, Michael H, Tewari KS (2015) Bevacizumab for advanced cervical cancer: patient-reported outcomes of a randomised, phase 3 tiral (NRG Oncology - Gynecologic Oncology Group protocol 240). Lancet Oncol 16(3): 301-311. 
R Core Team (2013) R: A Language and Environment for Statistical Computing. R Foundation for Statistical Computing: Vienna, Austria. Available at: http://www.R-project.org.

Rose PG, Java JJ, Whitney CW, Stehman FB, Lanciano R, Thomas GM (2014) Locally advanced adenocarcinomas and adneosquamous carcinomas of the cervix compared to squamous cell carcinomas of the cervix in Gynecologic Oncology Group trials of cisplatin-based chemoradiation. Gynecol Oncol 135(2): 208-212.

Sandler A, Gray R, Perry MC, Brahmer J, Schiller JH, Dowlati A, Lilenbaum R, Johnson DH (2006) Paclitaxel-carboplatin alone or with bevacizumab for non-small-cell lung cancer. N Engl J Med 355(24): 2542-2550.

Siegel RL, Miller KD, Jemal A (2017) Cancer statistics, 2017. CA Cancer J Clin 67(1): 7-30.

Silcocks PBS, Thornton-Jones H, Murphy M (1987) Squamous and adenocarcinoma of the uterine cervix: a comparison using routine data. Br J Cancer 55(3): 321-325.

Smith HO, Tiffany MF, Qualls CR, Key CR (2000) The rising incidence of adenocarcinoma relative to squamous cell carcinoma of the uterine cervix in the United States: a 24-year population-based study. Gynecol Oncol 78(2): 97-105.

Tewari KS, Sill MW, Long 3rd HJ, Penson RT, Huang H, Ramondetta LM, Landrum LM, Oaknin A, Reid TJ, Leitao MM, Michael HE, Monk BJ (2014) Improved survival with bevacizumab in advanced cervical cancer. N Engl J Med 370(8): 734-742.

Tewari KS, Sill MW, Monk BJ, Penson RT, Long 3rd HJ, Poveda A, Landrum LM, Leitao MM, Brown J, Reid TJ, Michael HE, Moore DH (2015) Prospective validation of pooled prognostic factors in women with advanced cervical cancer treated with chemotherapy with/without bevaiczumab: NRG Oncology/GOG study. Clin Cancer Res 21(24): 5480-5487.

Tewari KS, Sill MW, Penson RT, Huang H, Ramondetta LM, Landrum LM, Oaknin A, Reid TJ, Leitao MM, Michael HE, DiSaia PJ, Copeland LJ, Creasman WT, Stehman FB, Brady MF, Burger RA, Thigpen JT, Birrer MJ, Waggoner SE, Moore DH, Look KY, Koh WJ, Monk BJ (2017) Bevacizumab for advanced cervical cancer: final overall survival and adverse event analysis of a randomised, controlled, open-label, phase 3 trial (Gynecologic Oncology Group 240). Lancet 390: 1654-1663.

Wang SS, Sherman ME, Hildesheim A, Lacey Jr JV, Devesa S (2004) Cervical adenocarcinoma and squamous cell carcinoma incidence and trends among white women and black women in the United States for 1976-2000. Cancer 100(5): 1035-1044.

Wright AA, Howitt BE, Myers AP, Dahlberg SE, Palescandolo E, Van Hummelen P, MacConaill LE, Shoni M, Wagle N, Jones RT, Quick CM, Laury A, Katz IT, Hahn WC, Matulonis UA, Hirsch MS (2013) Oncogenic mutations in cervical cancer. Cancer 119(21): 3776-3783.

Young RH, Clement PB (2002) Endocervical adenocarcinoma and its variants: their morphology and differential diagnosis. Histopathology 41(3): 185-207.

This work is published under the standard license to publish agreement. After 12 months the work will become freely available and the license terms will switch to a Creative Commons AttributionNonCommercial-Share Alike 4.0 Unported License.

Supplementary Information accompanies this paper on British Journal of Cancer website (http://www.nature.com/bjc) 